\title{
Shoulder Girdle
}

National Cancer Institute

\section{Source}

National Cancer Institute. Shoulder Girdle. NCI Thesaurus. Code C33547.

The bony arch formed by the collarbones and shoulder blades. 